\title{
Education in surgery: motivation counts
}

\author{
F. M. Riegler
}

Published online: 11 May 2016

(C) Springer-Verlag Wien 2016

\section{Dear readers,}

this issue of European Surgery represents a very special spectrum of necessary and outstanding information. The enthusiastic personality of the president of the Austrian Surgical Society, Prof. Dr. Dietmar Öfner-Velano, motivated a broad-spectrum firework of highly stimulating papers dealing with an essential and very important topic: surgical education in Austria and Central Europe.

The future counts, and there will be no successful future if the present generation of teachers fail to care. In addition, young surgeons have to prepare themselves for their future: they will be the surgeons who will have to master and meet the requirements of the future (Fig. 1). Surgery can be minimal, invasive, complex, and interdisciplinary.

In this issue of European Surgery, Prof. ÖfnerVelano orchestrates an interdisciplinary symphony of papers covering all different aspects and modalities required for effective teaching and education in surgery. The spectrum covers all important aspects of the topic.

I thus hope that the readers will share my fascination for the papers published in this issue of European Surgery. Most importantly, this issue coincides with the upcoming annual meeting of the Austrian Society of Surgery in Salzburg, in May 2016. In line with the focus and major topic of the congress, the readers will find themselves within a beautiful colorful garden of possibilities (Fig. 1). In addition to flexibility and discipline, our world needs an open-minded approach to meet the health care requirements and challenges of the future.

\section{F. M. Riegler (函)}

Reflux Medical, Mariannengasse 10/9, 1090 Vienna, Austria e-mail: martin.riegler@refluxmedical.com

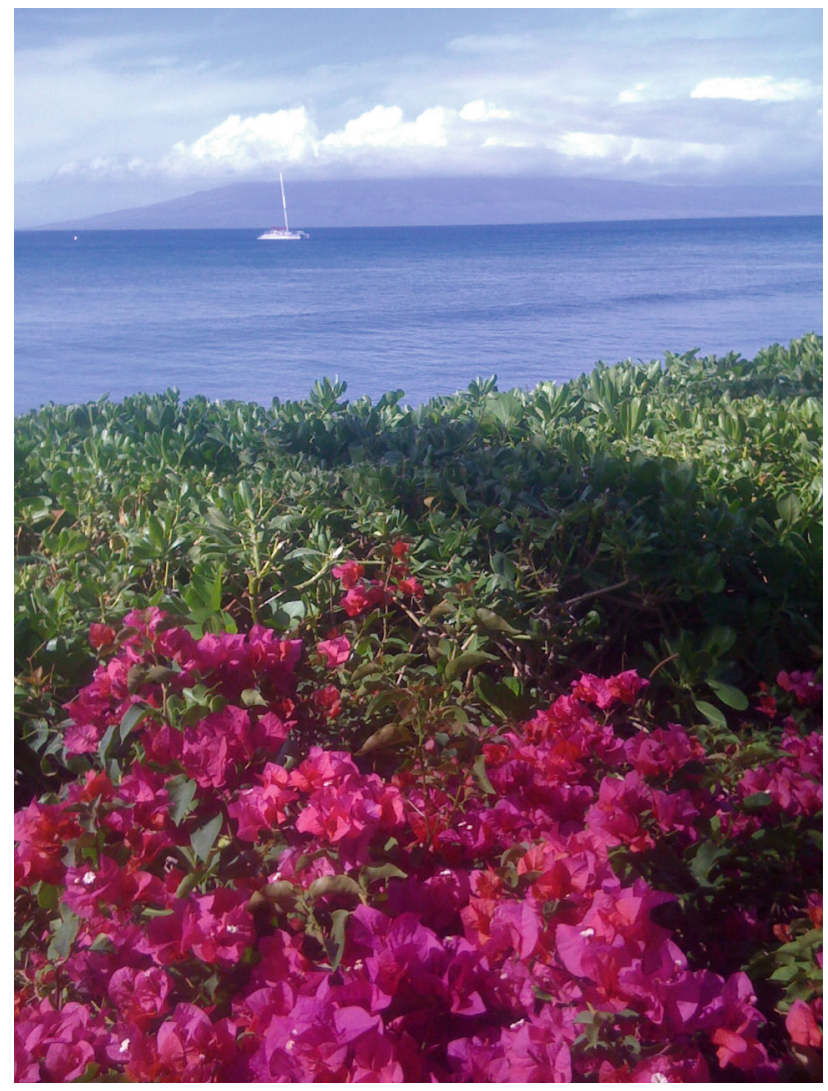

Fig. 1 The image mirrors the idea of the author, that teaching and education in surgery compares to the care required for the maintenance of a garden, where passion and discipline foster respective support and motivation to those who wish to flourish and bloom: true for teacher and scholar. Image obtained in Hawaii, using iPhone technology 


\section{editorial}

Taken together, and to make a short story shorter: motivation fosters success, success fosters satisfaction, and satisfaction fosters security. Thus let us be motivated to learn, teach, and educate for a well-designed, positively tuned modern surgery.
Stay tuned and enjoy your work,

\section{Martin Riegler}

Conflict of interest F. M. Riegler states that there are no conflicts of interest. 